\title{
Targeted Early Detection of Citrus Huanglongbing Causal Agent 'Candidatus Liberibacter asiaticus' Before Symptom Expression
}

\author{
Sheo Shankar Pandey ${ }^{1}$ and Nian Wang ${ }^{1,2, \dagger}$ \\ ${ }^{1}$ Citrus Research and Education Center, Department of Microbiology and Cell Science, University of Florida, Lake Alfred, FL 33850 \\ ${ }^{2}$ China-USA Citrus Huanglongbing Joint Laboratory (A joint laboratory of The University of Florida's Institute of Food and Agricultural \\ Sciences and Gannan Normal University), National Navel Orange Engineering Research Center, Gannan Normal University, Ganzhou 341000, \\ Jiangxi, China \\ Accepted for publication 17 January 2019.
}

\begin{abstract}
Citrus Huanglongbing (HLB) is the most severe disease of citrus plants caused by 'Candidatus Liberibacter asiaticus' and transmitted by the insect vector Asian citrus psyllid (ACP). No effective curative measure is available against HLB. For citrus production areas without HLB or with low HLB disease incidence, removal of ' $\mathrm{Ca}$. L. asiaticus' inoculum is critical to prevent HLB spread. Such a strategy requires robust early diagnosis of HLB for inoculum removal to prevent ACP acquisition and transmission of ' $\mathrm{Ca}$. L. asiaticus'. However, early diagnosis of HLB is challenging, because the citrus trees remain asymptomatic for several months to years after ' $\mathrm{Ca}$. L. asiaticus' transmission by ACP. In this study, we report a new method for targeted early detection of ' $\mathrm{Ca}$. L. asiaticus' in cultivar Valencia sweet orange (Citrus sinensis) before HLB symptom expression. We take advantage of the fact that ' $\mathrm{Ca}$. L. asiaticus' remains around the ACP feeding site immediately after transmission into the
\end{abstract}

ABSTRACT young flush and before flush maturation. ACPs secrete salivary sheaths at their feeding sites, which can be visualized using Coomassie brilliant blue staining owing to the presence of salivary sheaths secreted by ACP. Epifluorescence and confocal microscopy indicate the presence of salivary sheaths beneath the blue spots on ACP-fed leaves. Quantitative real-time polymerase chain reaction (PCR) and conventional PCR assays are able to detect ' $\mathrm{Ca}$. L. asiaticus' in the ACP feeding surrounding areas as early as 2 to 20 days after ACP feeding. This finding lays a foundation to develop much-needed tools for early diagnosis of HLB before symptom expression, thus assisting ' $\mathrm{Ca}$. L. asiaticus' inoculum removal and preventing HLB from spreading.

Keywords: citrus greening, phytopathogenic bacteria, plant disease control, psyllids salivary sheath.
Huanglongbing (HLB) is a devastating citrus disease that is caused, in most HLB-endemic areas, by a noncultured gramnegative $\alpha$-proteobacteria 'Candidatus Liberibacter asiaticus'. ' $C a$. L. asiaticus' is transmitted by the Asian citrus psyllid (ACP) Diaphorina citri Kuwayama 1907 (Hemiptera: Psyllidae) (Bové 2006; Grafton-Cardwell et al. 2013; Wang and Trivedi 2013; Wang et al. 2017). HLB-diseased plants exhibit blotchy mottle leaves, stunted growth, yellow shoot, reduced fruit size, corky vein, root decline, and ultimately, dieback (Bové 2006; Wang and Trivedi 2013; Wang et al. 2017). HLB was reported in Asian countries: China (Reinking 1919), India (1912; as “dieback") (Raychaudhuri et al. 1969), and the Philippines (1921; as "mottle leaf") (Lee 1921). Later, HLB was reported worldwide, including in South Africa (1929) (Oberholzer et al. 1965), Indonesia (1940s; as "phloem degeneration") (Aubert 1992), Brazil (2004) (Coletta-Filho 2004; Texeira et al. 2005), and Florida, U.S.A. (2005) (Halbert 2005). Currently, mature citrus trees are almost $100 \%$ HLB positive, and $>75 \%$ reduction in gross citrus production in Florida has been caused by HLB (Milne et al. 2018).

All commercial citrus varieties are susceptible to HLB. HLB management in citrus-producing areas without HLB or with low HLB incidence relies on quarantine measures, psyllid control,

†Corresponding author: N. Wang; nianwang@ufl.edu

Funding: This study has been supported by U.S. Department of Agriculture National Institute of Food and Agriculture grant 2018-70016-27412 (to N. Wang) and the Florida Citrus Research and Development Foundation.

*The $e$-Xtra logo stands for "electronic extra" and indicates that six supplementary figures are published online.

The author(s) declare no conflict of interest.

(c) 2019 The American Phytopathological Society removal of diseased trees, and replanting with HLB-free trees. HLB inoculum removal is primarily based on visual observation of disease symptoms and confirmation with quantitative polymerase chain reaction (qPCR). However, the infected plants remain asymptomatic for several months to years, making the symptom-based diagnosis ineffective for inoculum removal. Individual ACP adults, after acquisition feeding on infected plants for 20 days, can transmit ' $\mathrm{Ca}$. L. asiaticus' to healthy plants at $80 \%$ efficiency (Xu et al. 1988). The emerging ACP adults from the nymphal stage can transfer ' $\mathrm{Ca}$. L. asiaticus' with $67 \%$ efficiency after an inoculation access period of 30 days (Inoue et al. 2009). However, a study in Florida showed 5\% ' $\mathrm{Ca}$. L. asiaticus' transmission efficiency by individual ACP adult and $73 \%$ by a group of 200 emerging ACP adults after 30 days of an inoculation access period (Pelz-Stelinski et al. 2010). Variable transmission efficiency, infection establishment, and an asymptomatic period make it difficult to identify the ' $\mathrm{Ca}$. L. asiaticus' infection at a definite time after the first inoculation. Early diagnosis of HLB and/or early detection of ' $\mathrm{Ca}$. L. asiaticus' before symptom expression have been deemed a priority for HLB management to prevent HLB from becoming epidemic.

The plant-feeding hemipterans secrete gel saliva while probing and feeding on the plant leaves, which forms a salivary sheath encapsulating the insect's mouthpart (i.e., stylet) (Backus et al. 2005; Brennan et al. 2001; Miles 1972; Morgan et al. 2013). Initially, the phytophagous insect releases gel saliva on the surface of the leaf or stem, which serves as a holdfast for initiation of stylet penetration across the cuticle, epidermis, and mesophylls (Miranda et al. 2009; Wang et al. 2008). The saliva gel on the leaf surface forms a "flange" and continues below the surface as a "sheath neck" followed by a "sheath trunk," which further extends to the vascular region as branched or unbranched bulbous structures (Bonani et al. 2010; Brennan et al. 2001; Miranda et al. 2009; Morgan et al. 2013; Wang et al. 2008). The precise function of the salivary sheath is ambiguous. 
However, it has been regarded as a lubricating substance to facilitate stylet advancement and retraction and protect it from mechanical and chemical damages (van der Westhuizen et al. 1998; Will et al. 2012). During the inoculation process, ACP transmits ' $\mathrm{Ca}$. L. asiaticus' into the sieve elements of a recipient citrus plant together with salivary secretions during feeding. In addition, it has been shown that ' $\mathrm{Ca}$. L. asiaticus' moves with phloem sap from source to sink tissues and remains in the young flush after ACP transmission and before the young flush matures (M. Andread and N. Wang, unpublished data). Thus, the phloem tissues surrounding the ACP feeding sites are expected as possible places for early detection of ' $\mathrm{Ca}$. L. asiaticus' before symptom expression.

In this study, we used Coomassie brilliant blue staining of the flanges, an external part of the salivary sheaths, to identify the feeding sites of psyllids. ' $C a$. L. asiaticus' surrounding the ACP feeding sites was detected using microscopic analysis, qPCR, and conventional polymerase chain reaction (PCR) analyses. Findings of this study provide a unique opportunity for targeted early detection of ' $\mathrm{Ca}$. L. asiaticus' before symptom expression, thus assisting in inoculum removal to control HLB.

\section{MATERIALS AND METHODS}

Psyllids and host plant. ACP was maintained on ' $\mathrm{Ca}$. L. asiaticus'-infected cultivar Valencia trees in the greenhouse at $24 \pm$ $2{ }^{\circ} \mathrm{C}$, controlled light ( $16 \mathrm{~h}$ light and $8 \mathrm{~h}$ dark) and relative humidity of $50 \pm 5 \%$. Five-month-old seedlings of Valencia sweet orange with young flush were used for ACP transmission of ' $\mathrm{Ca}$. L. asiaticus'.

Coomassie brilliant blue staining. The Valencia seedlings were caged separately with 15 psyllids in each cage. Two leaves were collected from each seedling, with a minimum of three seedlings at different time intervals. The leaves were incubated in $0.1 \%$ Coomassie brilliant blue at room temperature for $30 \mathrm{~min}$ and then distained in water for $20 \mathrm{~min}$. The Coomassie brilliant blue stains the flanges of psyllid salivary sheaths, which are indicated by blue spots. The images were taken using a stereomicroscope (Swift Table Stereo Zoom Microscope). The leaf tissues with blue spots were further dissected and analyzed under epifluorescence and confocal microscopes. The tissues around the salivary flange blue spots, including nearest veins, were collected for genomic DNA extraction and ' $\mathrm{Ca}$. L. asiaticus' detection using qPCR and conventional PCR.

Sectioning and microscopy. The leaf tissues around the blue spots on Coomassie brilliant blue-stained Valencia leaves were collected using a surgical knife under a stereomicroscope (Swift Table Stereo Zoom Microscope). The leaf tissues were fixed in $4 \%$ paraformaldehyde for $24 \mathrm{~h}$. Then, the tissues were dehydrated by keeping for $1 \mathrm{~h}$ each in 30,50,70,85,95\%, and absolute ethanol. Later, the slides were placed in 33, 50, 60, and 100\% tert-Butanol (Fisher Scientific) for $1 \mathrm{~h}$ each. The tissues were embedded in paraffin and dissected into thin slices of $10-\mu \mathrm{m}$ thickness using a motorized microtome (Leica RM 2155 Rotary Microtome; Leica Biosystems Inc.). The slides were incubated in a slide warmer overnight. The slides were incubated twice in Histo-Clear II (National Diagnostics) for $1 \mathrm{~h}$ to remove the paraffin. The samples were rehydrated by placing slides in 100, 75, and 50\% ethanol for 5 to 10 min each and then, in water for $5 \mathrm{~min}$. For immunolabeling, the samples were treated with primary antibody against OmpA (anti-OmpA) for $2 \mathrm{~h}$ at room temperature and then washed in $1 \times$ phosphate buffer saline (PBS). Furthermore, the samples were treated with a fluorescent secondary antibody for $1 \mathrm{~h}$ and again washed in $1 \times \mathrm{PBS}$. We used a microtome cryostat for rapid frozen sectioning of the fixed leaf tissues embedded in Tissue-Tek O.C.T. compound (formulation

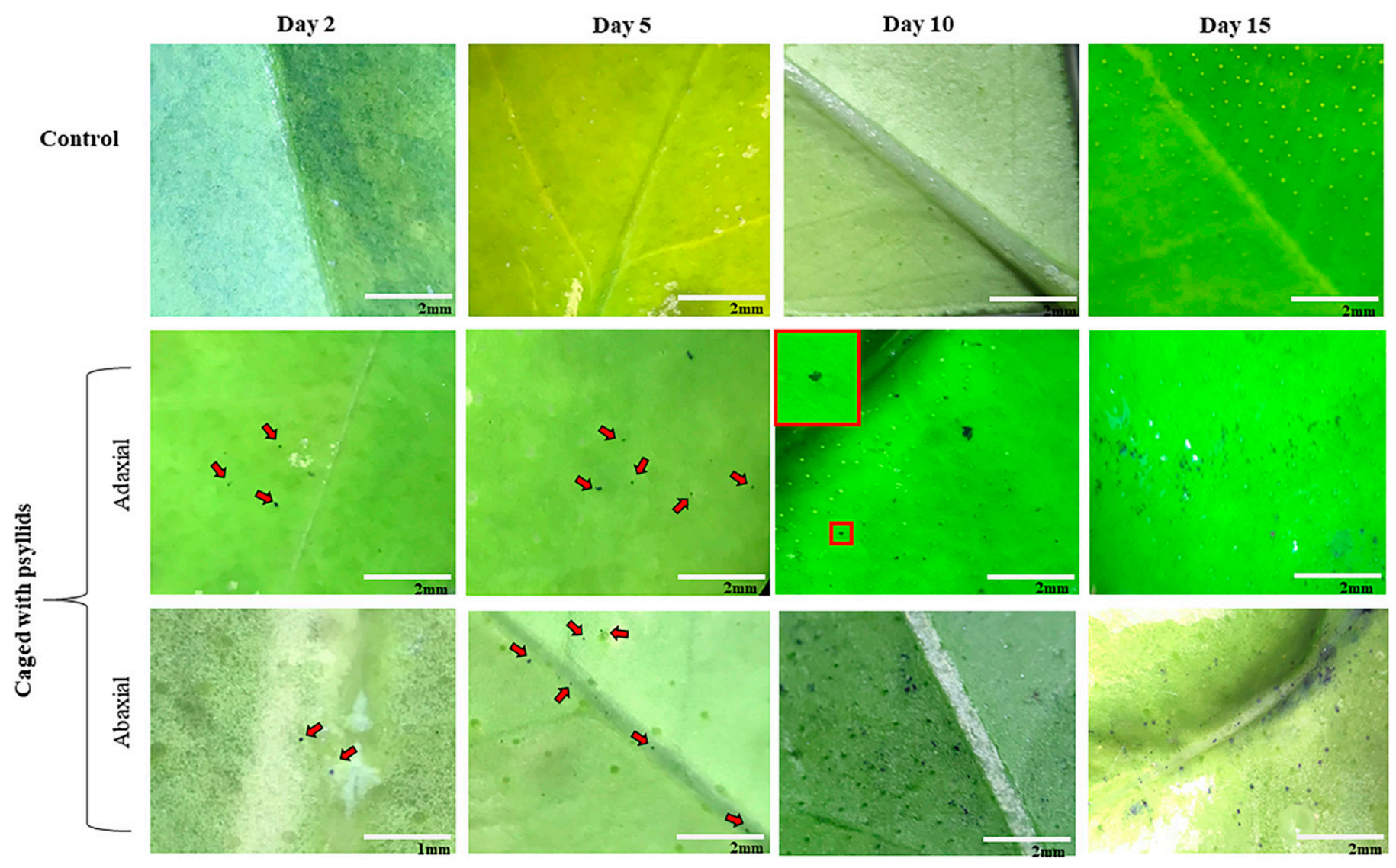

Fig. 1. Coomassie brilliant blue staining of psyllid salivary flanges on the cultivar Valencia sweet orange leaves. The 5-month-old seedlings of Valencia sweet orange were caged with 15 Asian citrus psyllid each. The psyllids were released at different time intervals ( 2 to 20 days), and leaves were stained with Coomassie brilliant blue. The stained psyllid salivary flanges were observed under a stereomicroscope. The red arrows indicate the Coomassie brilliant blue-stained flanges. Inset, Enlarged view of a flange. 


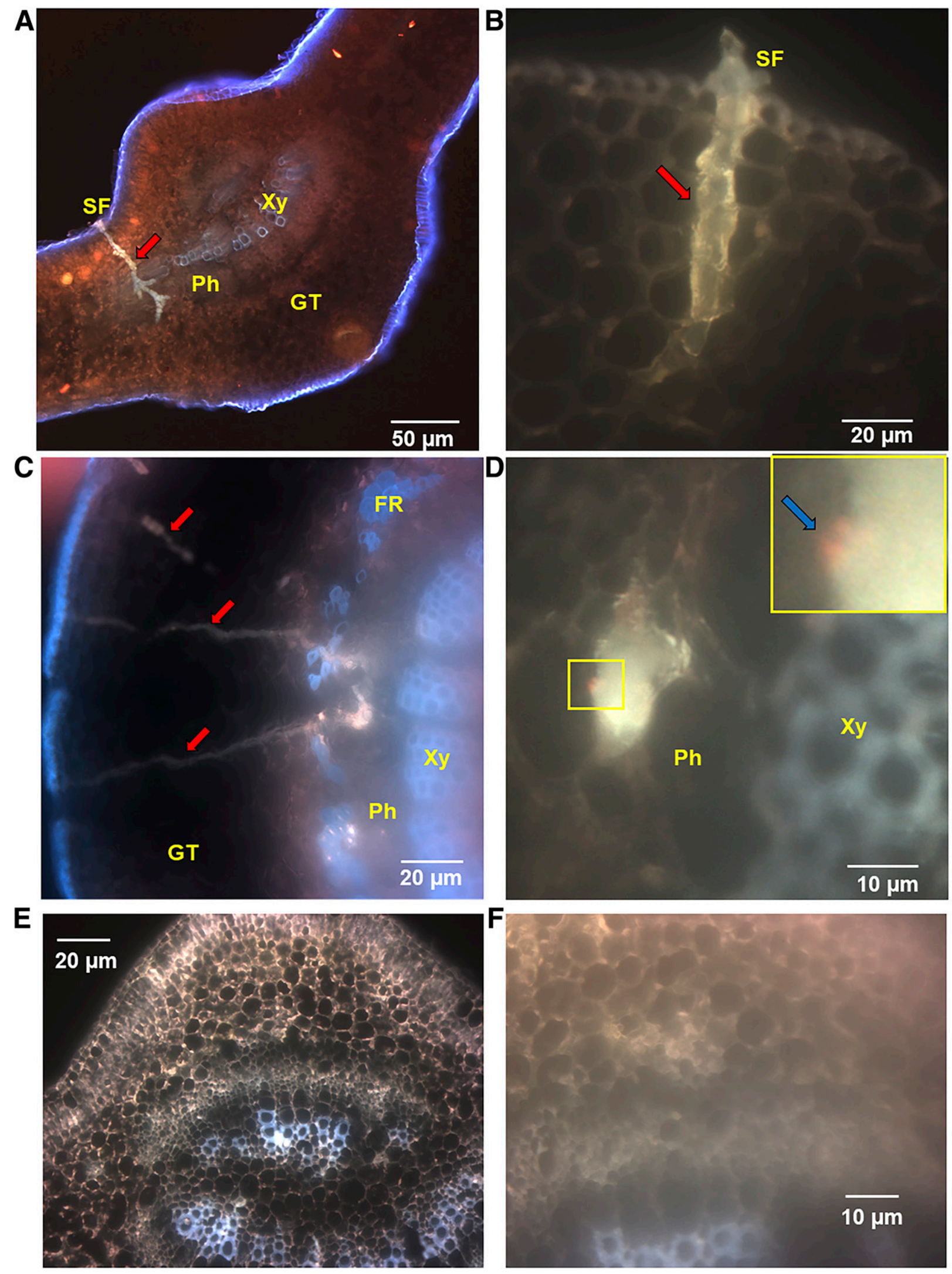

Fig. 2. The psyllid salivary sheath inside the leaves. Visualization of the psyllid salivary sheaths using an epifluorescence microscope. A and $\mathbf{C}$, The cryosections of flange containing cultivar Valencia leaves fed by psyllids for 5 and 15 days, respectively. B and D, The dehydrated cross-sections of Valencia leaves fed by psyllids for 7 days. $\mathbf{E}$ and $\mathbf{F}$, Untreated controls at different magnification. Red arrows indicate the salivary sheath. The blue arrow indicates the red fluorescing 'Candidatus Liberibacter asiaticus' against the antibodies against OmpA. Inset, Enlarged view of a part of the salivary sheath displaying red fluorescing ' $\mathrm{Ca}$. L. asiaticus'. FR, fibrous ring; GT, ground tissue; Ph, phloem; SF, salivary flange; Xy, xylem. 
of glycols and resins; VWR). The microsections of the leaf tissues were analyzed under an epifluorescence microscope (Olympus BX61; Olympus Corporation). The confocal laser scanning microscopy was performed using a Leica SP8 Multiphoton system (Leica Biosystems Inc.), and the images were analyzed using Leica LasX software (Leica Biosystems Inc.).

' $C a$. L. asiaticus' genomic DNA extraction from ACP. 'Ca. L. asiaticus' genomic DNA from ACP was extracted as described previously (Hung et al. 2004; Sambrook et al. 1989) with modifications. Briefly, powdered ' $\mathrm{Ca}$. L. asiaticus'-infected psyllids were transferred to $200 \mu \mathrm{l}$ of extraction buffer $(50 \mathrm{mM}$ Tris $\cdot \mathrm{Cl}$, $\mathrm{pH}$ 8.0, $10 \mathrm{mM}$ EDTA, and RNase A at $100 \mu \mathrm{g} / \mathrm{ml}$ ) and then incubated at $50^{\circ} \mathrm{C}$ for $1 \mathrm{~h}$ with lysozyme at $0.25 \mathrm{mg} / \mathrm{ml}$ and $80 \mu \mathrm{l}$ of $10 \%$ sodium dodecyl sulfate (SDS). Samples were then treated with
$100 \mu \mathrm{M}$ proteinase $\mathrm{K}$ over-night at $37^{\circ} \mathrm{C}$. The next day, samples were incubated at $65^{\circ} \mathrm{C}$ for $30 \mathrm{~min}$ with $400 \mu \mathrm{l}$ of preheated cetyltrimethylammonium bromide $(\mathrm{CTAB}) / \mathrm{NaCl}(10 \% \mathrm{CTAB}$ and $0.7 \mathrm{M} \mathrm{NaCl}$ ). Samples were then treated with $1 \mathrm{ml}$ of chloroform and isoamyl alcohol (24:1) and $1 \mathrm{ml}$ of phenol, chloroform, and isoamyl alcohol $(25: 24: 1)$. DNA from the aqueous phase was precipitated using $170 \mu \mathrm{l}$ of sodium acetate $(3 \mathrm{M}, \mathrm{pH} 7)$ and $700 \mu \mathrm{l}$ of iso propanol at $-20^{\circ} \mathrm{C}$ for $1 \mathrm{~h}$. The DNA pellet was washed with $200 \mu \mathrm{l}$ of $70 \%$ ethanol before being resuspended in $\mathrm{H}_{2} \mathrm{O}$.

Genomic DNA extraction from healthy or ' $\mathrm{Ca}$. $\mathrm{L}$. asiaticus'-infected Valencia leaves. For ' $C a$. L. asiaticus' detection, the 4- $\mathrm{mm}^{2}$ leaf area surrounding the flange was collected with a sterile scalpel. The leaf areas around the flanges on or near the midrib, veins, and small netted veins were considered as potential
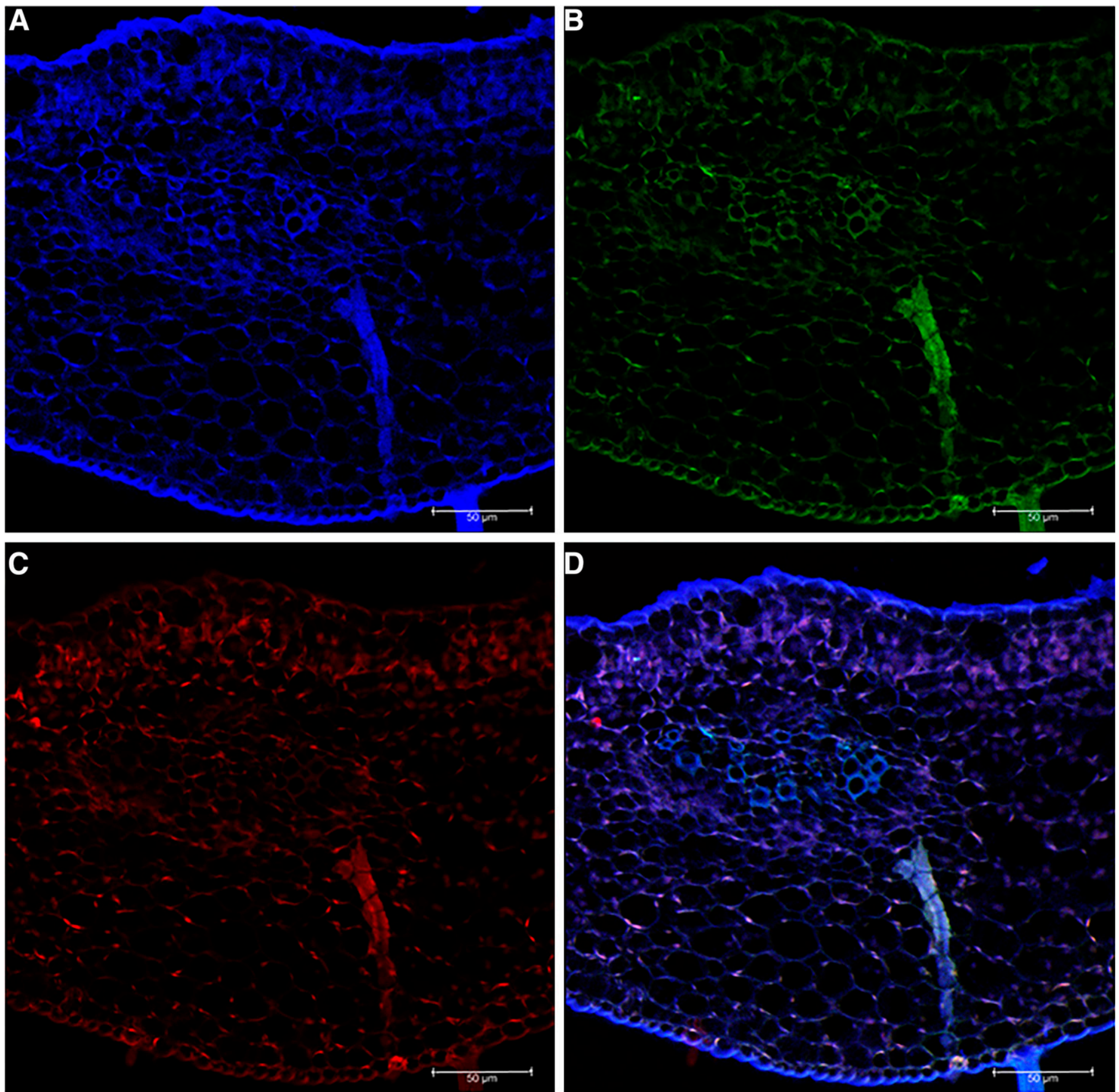

Fig. 3. Visualization of psyllid salivary sheath under a confocal microscope. The psyllid salivary sheath exhibits autofluorescence under A, blue, B, green, and $\mathbf{C}$, red regions of wavelength. D, Merged. 
places to detect ' $\mathrm{Ca}$. L. asiaticus'. A 4-mm² clean area of leaves 2 $\mathrm{cm}$ away from the flange was also collected as a control. Collected leaf discs were transferred to centrifugation tubes, submerged in liquid nitrogen, and then powdered using a TissueLyser II (Qiagen). Genomic DNA from powdered leaf samples was extracted using a DNeasy Plant Mini Kit (Qiagen) following the manufactur-er's instructions.

' $C a$. L. asiaticus' detection using real-time qPCR and conventional PCR. qPCR for ' $\mathrm{Ca}$. L. asiaticus' detection was performed as described previously (Wang et al. 2006). All qPCR experiments were performed using Quantitect Probe PCR master mix (Qiagen) following the manufacturer's instruction. The primers CQULA04F (5'-TGGAGGTGTAAAAGTTGCCAAA-3'), and CQULA04R (5'-CCAACGAAAAGATCAGATATTCCTCTA-3') and the probe CQULAP10 (5'-ATCGTCTCGTCAAGATTGC TATCCGTGATACTAG-3') were used (Wang et al. 2006). The 5' end of the probe was labeled with a 6-FAM (6- corboxy fluorescein amidite) reporter fluorescent dye, whereas the $3^{\prime}$ end was labeled with a TAMRA (6-carboxy-N, $\mathrm{N} \mathrm{N}^{\prime}, \mathrm{N}^{\prime}$-tetramethylrhodamine) quencher dye. The qPCR was conducted using a QuantStudio 3 Real-Time PCR System (Thermo Fisher Scientific). Conventional PCR was performed using the Phusion High-Fidelity DNA Polymerase (NEB) or Q5 High-Fidelity DNA Polymerase (NEB). The primers CQULA04F and CQULA04R were used for conventional PCR and sequencing of PCR products.

\section{RESULTS}

Coomassie brilliant blue stains the flanges of the psyllid salivary sheath on the Valencia leaf surface. Hemipterans produce salivary sheaths while feeding on the leaf or stem surfaces of host plants. The flanges of salivary sheaths remain on the leaf surface, and they contain multiple salivary proteins. A total of $86 \mathrm{ACP}$ proteins were identified from the salivary sheaths of ACP feeding on an artificial diet (Yu and Killiny 2018). Coomassie brilliant blue dye interacts electrostatically but noncovalently with the amino and carboxyl groups of proteins. To assess whether psyllid flanges were stained with Coomassie blue, we used the young leaves of 5-monthold Valencia seedlings caged with ACP for 2, 5, 10, 15, and 20 days. The results showed the presence of flanges as blue spots on both abaxial and adaxial surfaces of leaves (Fig. 1). The young leaves from a 5-year-old Valencia tree in the grove and a 2-year-old Valencia seedlings kept in the greenhouse with ' $\mathrm{Ca}$. L. asiaticus'-positive ACP for 6 months exhibited stained flanges on both sides of the leaf (Supplementary Fig. S1). The presence of flanges correlates with the feeding behavior of ACPs, which were observed feeding on both adaxial and abaxial surfaces of leaves (Supplementary Fig. S2).

Microscopic observation of psyllid salivary sheaths and ' $\boldsymbol{C a}$. L. asiaticus' cells inside plant tissues. To investigate the presence of salivary sheaths in continuation of flanges inside the leaf, we dissected the leaf tissues containing Coomassie brilliant blue-stained spots and analyzed the cross-sections under an epifluorescence microscope. We exploited the autofluorescence to detect salivary sheaths under the epifluorescence microscope. The results suggested the continuation of flanges as salivary sheaths inside the leaf tissues through cuticle, epidermis, mesophyll, and phloem (Fig. 2A to C). The anti-OmpA (' $\mathrm{Ca}$. L. asiaticus' outer membrane protein) treatment of cross-sections and detection using red fluorescent secondary antibody showed the presence of possible 'Ca. L. asiaticus' cells near psyllid salivary sheaths (Fig. 2D). Confocal microscopy also confirms the presence of salivary sheaths, which displayed the autofluorescence under ranges of wavelengths (Fig. 3; Supplementary Fig. S3).

Detection of ' $\mathrm{Ca}$. L. asiaticus' near the salivary sheaths using real-time qPCR. To investigate whether we can detect ' $\mathrm{Ca}$. L. asiaticus' around the salivary sheaths, we performed qPCR

TABLE 1. Quantitative polymerase chain reaction-based quantification of 'Candidatus Liberibacter asiaticus' at different time points ${ }^{\mathrm{a}}$

\begin{tabular}{|c|c|c|c|c|c|c|c|}
\hline \multirow[b]{2}{*}{$\begin{array}{l}\text { ACP feeding period on } \\
\text { cultivar Valencia (days) }\end{array}$} & \multicolumn{2}{|c|}{$\begin{array}{l}\text { 'Ca. L. asiaticus' } \\
\text { titer in psyllid }\end{array}$} & \multicolumn{2}{|c|}{$\begin{array}{c}\mathrm{C}_{\mathrm{t}} \text { values for ' } \mathrm{Ca} \text {. } \mathrm{L} \text {. asiaticus' in } \\
\text { the leaves on the day of ACP } \\
\text { removal }\end{array}$} & \multirow{2}{*}{$\begin{array}{l}\mathrm{C}_{\mathrm{t}} \text { values for } \\
\text { 'Ca. } \mathrm{L} \text {. asiaticus' } \\
\text { at } 30 \mathrm{dpi}\end{array}$} & \multicolumn{2}{|c|}{ 'Ca. L. asiaticus' titer at 60 dpi } \\
\hline & $\mathrm{C}_{\mathrm{t}}$ value & $\begin{array}{c}\text { Genome equivalents } \\
\mu \mathrm{g}^{-1} \text { total DNA }{ }^{\mathrm{b}}\end{array}$ & Treated & Untreated control & & $\mathrm{C}_{\mathrm{t}}$ values & $\begin{array}{c}\text { Genome equivalents } \\
\mu \mathrm{g}^{-1} \text { total DNA }{ }^{\mathrm{b}}\end{array}$ \\
\hline 2 & $22.57 \pm 2.7$ & $3.06 \times 10^{6}$ & $38.35 \pm 1.3$ & UD & $37.76 \pm 0.98$ & $28.98 \pm 0.18$ & $5.18 \times 10^{4}$ \\
\hline 5 & $21.95 \pm 0.9$ & $4.56 \times 10^{6}$ & $U^{c}$ & $U^{d}$ & $36.95 \pm 0.38$ & $27.07 \pm 0.15$ & $1.57 \times 10^{5}$ \\
\hline 10 & $22.81 \pm 2.8$ & $2.61 \times 10^{6}$ & $36.83 \pm 1.3$ & UD & $37.98 \pm 0.13$ & $28.84 \pm 0.74$ & $4.27 \times 10^{4}$ \\
\hline Untreated & - & - & - & - & UD & UD & UD \\
\hline
\end{tabular}

a Cycle threshold $\left(\mathrm{C}_{t}\right)$ values are mentioned only if detected in all three replicates; otherwise, they are referred to as undetermined (UD). However, the means of each repeat if any of the $\mathrm{C}_{\mathrm{t}}$ value was detected are mentioned below. Values are mean \pm standard deviation; $n=3$. ACP, Asian citrus psyllid; dpi, days postinoculation.

b Genome equivalents micrograms ${ }^{-1}$ of total DNA for ' $\mathrm{Ca}$. L. asiaticus' titer are calculated as described previously (Trivedi et al. 2009) from the mean $\mathrm{C}_{\mathrm{t}}$ values mentioned in preceding column.

${ }^{c} \mathrm{C}_{\mathrm{t}}-1$, UD; $\mathrm{C}_{\mathrm{t}}-2,39.47 ; \mathrm{C}_{\mathrm{t}}-3,38.54$.

${ }^{d} \mathrm{C}_{\mathrm{t}}-1, \mathrm{UD} ; \mathrm{C}_{\mathrm{t}}-2,38.65 ; \mathrm{C}_{\mathrm{t}}-3$, UD.

${ }^{\text {e }} \mathrm{C}_{\mathrm{t}}-1, \mathrm{UD} ; \mathrm{C}_{\mathrm{t}}-2$, UD; $\mathrm{C}_{\mathrm{t}}-3,39.48$.

TABLE 2. Quantitative polymerase chain reaction-based quantification of 'Candidatus Liberibacter asiaticus' in tissues next to and away from Asian citrus psyllid feeding sites ${ }^{\mathrm{a}}$

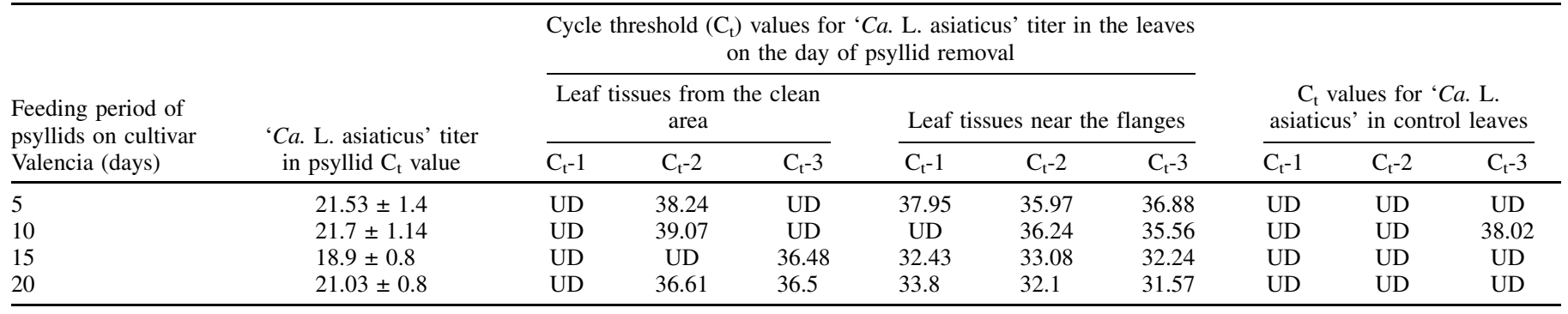

${ }^{\mathrm{a}} \mathrm{UD}$, undetermined. 
analysis using genomic DNA isolated from the leaf tissues around the flanges stained with Coomassie brilliant blue as a template. The leaf samples were collected at different time intervals after ACP feeding. After removal of the psyllids from the cage, Valencia seedlings were kept in psyllid-free condition for additional analysis. The infected psyllids used for feeding on Valencia seedling exhibited cycle threshold $\left(\mathrm{C}_{\mathrm{t}}\right)$ values of 21.95 to 26.66 , which correspond to $4.56 \times 10^{6}$ to $1.14 \times 10^{6}$ ' $\mathrm{Ca}$. L. asiaticus' genome equivalents $\mu \mathrm{g}^{-1}$ of total DNA (Table 1). The $\mathrm{C}_{\mathrm{t}}$ values in Valencia leaves ranged from 36.83 to 38.35 after 2 to 20 days of ACP feeding (Table 1). The conventional PCR using the primer pair CQULA04F/ CQULA04R and subsequent sequencing confirmed the presence of ' $C a$. L. asiaticus' on the 2nd and 10th days of ACP feeding (Supplementary Fig. S4). Furthermore, the leaves exhibited $\mathrm{C}_{\mathrm{t}}$ values ranging between 36.6 and 37.98 at 30 days postinoculation (dpi; considering from the first day of ACP feeding), which substantially increased to 25.68 to 28.98 at 60 dpi (Table 1 ).
Furthermore, we performed an experiment to compare the ' $\mathrm{Ca}$. L. asiaticus' titer between the leaf tissues near the salivary sheaths and the tissues away from the salivary sheaths. We collected the leaves after 5, 10, 15, and 20 days of psyllids feeding and stained them with Coomassie brilliant blue. The genomic DNA was isolated from the tissues of a $4-\mathrm{mm}^{2}$ area around flanges and the tissues from clean areas $2 \mathrm{~cm}$ away from the flanges. The tissues around the flanges displayed $\mathrm{C}_{t}$ values ranging from 31.57 to 37.95 after 5 to 20 days of ACP feeding (Table 2), whereas most samples from clean areas were ' $C a$. L. asiaticus' negative, with few samples displaying $C_{t}$ values ranging from 36.53 to 39.07 (Table 2). Interestingly, conventional PCR and sequencing confirmed the presence of ' $C a$. L. asiaticus' only in leaf tissues around salivary sheaths after 15 and 20 days of ACP feeding. The nucleotide bands of specific size, indicated by red line-bordered squares in Supplementary Figure S5, were purified and sent for sequencing. The blast search
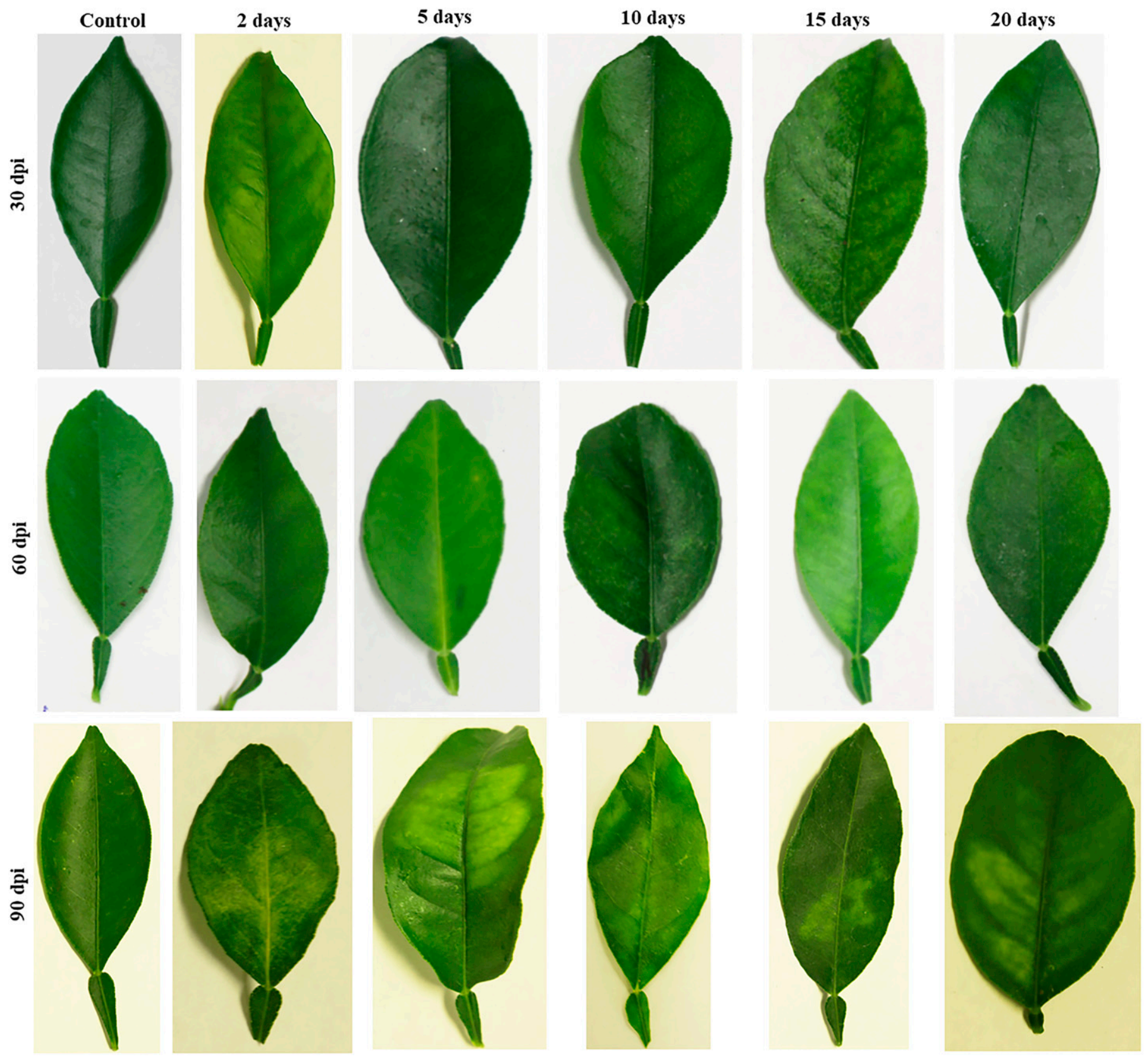

Fig. 4. Early development of Huanglongbing (HLB) symptoms. The appearance of HLB symptoms in 5-month-old cultivar Valencia seedlings fed by Asian citrus psyllid for 2 to 20 days. The HLB symptoms were monitored at 30, 60, and 90 days postinoculation (dpi). Representative images of HLB symptom development are shown. 
analysis of sequencing results confirmed the presence of ' $\mathrm{Ca}$. L. asiaticus'.

Symptomatic development of HLB in Valencia leaves after psyllids feeding. To analyze the HLB symptom development at an early stage, we monitored the phenotypic changes in Valencia leaves up to 3 months after ACP feeding. The Valencia leaves did not exhibit substantial phenotypic changes at 2 months after ACP feeding (Fig. 4). Early blotchy mottle symptoms appeared after $90 \mathrm{dpi}$, and plants displayed both asymptomatic and symptomatic leaves (Fig. 4; Supplementary Fig. S6).

\section{DISCUSSION}

HLB is the most devastating citrus disease worldwide, and there are no effective control measures available after the trees become infected by ' $\mathrm{Ca}$. L. asiaticus'. One of the critical control measures for HLB management is the removal of HLB-diseased citrus plants to prevent further spread. Successful eradication relies on robust and early diagnosis of HLB-diseased trees before they can serve as inoculum. Traditionally, diagnosis is based on visual observation and qPCR confirmation (Li et al. 2006). However, citrus remains asymptomatic for several months to years after ' $\mathrm{Ca}$. L. asiaticus' transmission (Gottwald 2010; Gottwald et al. 2007; Lee et al. 2015). qPCR has not been successfully used for targeted early diagnosis of HLB before symptom expression because of the uneven distribution of ' $\mathrm{Ca}$. L. asiaticus' in planta (Tatineni et al. 2008). This study allows for a targeted early detection of ' $\mathrm{Ca}$. L. asiaticus' within 2 to 20 days of initial inoculation of Valencia sweet orange before HLB symptom appearance, and thus, it has the potential to significantly assist inoculum removal to control HLB. This targeted early detection of ' $\mathrm{Ca}$. L. asiaticus' before HLB symptom expression allows regulatory agencies to conduct early diagnoses of HLB in California and other non-HLBendemic regions. In practice, citrus groves found with ACP can be screened for ' $\mathrm{Ca}$. L. asiaticus' on trees, especially young flush, fed by ACP using this method. Combined with monitoring the ACP population and testing ' $\mathrm{Ca}$. L. asiaticus' infection rates of ACP in citrus groves, early detection of ' $\mathrm{Ca}$. L. asiaticus' in citrus before symptom expression will help remove inoculum and prevent ACP transmission of ' $\mathrm{Ca}$. L. asiaticus'. In addition, ACP feeding sites identified with Coomassie brilliant blue can also help develop other early ' $C a$. L. asiaticus' detection tools (e.g., based on immunoblotting or sequencing). Despite the potential applications of this method, depending on the ' $\mathrm{Ca}$. L. asiaticus' titers in $\mathrm{ACP}$ and the length of the feeding period, challenges remain for ' $C a$. L. asiaticus' detection during the early days after transmission owing to low titers of ' $\mathrm{Ca}$. L. asiaticus'.

The phytophagous hemipterans excrete gel saliva during probing, which turns into a salivary flange and may continue as a sal-ivary sheath inside the leaf (Miles 1972; Morgan et al. 2013). The Coomassie brilliant blue staining of the proteins present in the salivary flanges of ACP can be used to identify the feeding spots on Valencia sweet orange leaves. However, some Coomassie brilliant blue-stained spots on the leaf surface do not extend as salivary sheaths inside the leaf tissue. A previous study suggested that only $47 \%$ of the flanges continue as salivary sheaths after probing by planthoppers on rice leaves (Wang et al. 2008). Another possible reason is a nonspecific staining of some other insect's excretory substances on the leaves. The ACP probing phenomenon on leaf surfaces appears random; however, they can only feed if they probe at the right place near the vascular system. Therefore, the leaf tissues around the flange near the midrib, veins, and small netted veins can be expected to have the enriched ' $\mathrm{Ca}$. L. asiaticus' titer.

' $C a$. L. asiaticus' can be detected with certainty at 60 days postACP transmission with $C_{t}$ values ranging from 25.68 to 28.98 . Detection of ' $\mathrm{Ca}$. L. asiaticus' at 30 days post-ACP feeding is less certain with higher $C_{t}$ values of 36.83 to 38.35 , indicating low ' $\mathrm{Ca}$. L. asiaticus' titers. A $\mathrm{C}_{\mathrm{t}}$ value of $>30$ is less consistent, and the citrus plants that are ' $\mathrm{Ca}$. L. asiaticus' positive must be confirmed by conventional PCR and/or immunostaining. A low genomic DNA ratio of ' $C a$. L. asiaticus' to host plant $(1: 1,000)$ (Li et al. 2006) makes it difficult to detect the bacteria in infected plants. The early stage of infected plants might have a lower genomic DNA ratio of ' $\mathrm{Ca}$. L. asiaticus' to host plants. As expected, ' $C a$. L. asiaticus' was detected in tissues surrounding ACP feeding sites but at much lower titers in tissues away from feeding sites, further confirming targeting of ACP feeding sites for detection purposes.

Notably, the Valencia leaves did not display a substantial change in phenotype, and plants remained asymptomatic for HLB even after 60 dpi (Fig. 4). However, HLB-like symptoms were observed on Valencia leaves at 90 dpi (Fig. 4). This further confirms that targeted detection of ' $\mathrm{Ca}$. L. asiaticus' around ACP feeding sites allows for early diagnosis of HLB long before symptom expression. It is pertinent to note that the Valencia seedlings fed by ' $\mathrm{Ca}$. L. asiaticus'infected ACP for 2 days also displayed the HLB symptoms. The results suggest that the ACP with enough ' $\mathrm{Ca}$. L. asiaticus' inoculum can transmit the bacteria successfully even after a short feeding period (Fig. 4 and Tables 1 and 2) (Ammar et al. 2013).

Several studies, including this one, suggest an undetermined pattern of HLB infection and symptom development. The infected citrus plants remain asymptomatic for an undefined period, which makes it difficult to diagnose HLB solely based on symptoms. This study implies that the early detection of ' $\mathrm{Ca}$. L. asiaticus' on infected plants can be achieved using qPCR, conventional PCR, and immunoblotting while tracking the ACP salivary sheath. In the field, ACP prefers to feed on young flush of the citrus tree. Therefore, the young flush from the groves suspected of having ' $C a$. L. asiaticus' infection can be diagnosed in the early stage very precisely by application of the Coomassie brilliant blue staining coupled with microscopy, qPCR, conventional PCR, and immunoblotting.

\section{ACKNOWLEDGMENTS}

We thank D. L. Stanton from the microscopy laboratory of the Citrus Research and Education Center/Institute of Food and Agricultural Sciences, University of Florida for his help during epifluorescence and confocal microscopy. We also thank E. Watson Carter for critical reading of this manuscript.

\section{LITERATURE CITED}

Ammar, E.-D., Walter, A. J., and Hall, D. G. 2013. New excised-leaf assay method to test inoculativity of Asian citrus psyllid (hemiptera: psyllidae) with Candidatus Liberibacter asiaticus associated with citrus Huanglongbing disease. J. Econ. Entomol. 106:25-35.

Aubert, B. 1992. Citrus greening disease, a serious limiting factor for citriculture in Asia and Africa. Pages 817-820 in: Proceedings of the 7th International Citrus Congress. Cultural practices, diseases and their control. E. Tribulato, A. Gentile, and G. Reforgiato, eds. ISC (International Citrus Congress), Acireale, Italie.

Backus, E. A., Serrano, M. S., and Ranger, C. M. 2005. Mechanisms of hopperburn: An overview of insect taxonomy, behavior, and physiology. Annu. Rev. Entomol. 50:125-151.

Bonani, J. P., Fereres, A., Garzo, E., Miranda, M. P., Appezzato-Da-Gloria, B., and Lopes, J. R. S. 2010. Characterization of electrical penetration graphs of the Asian citrus psyllid, Diaphorina citri, in sweet orange seedlings. Entomol. Exp. Appl. 134:35-49.

Bové, J. M. 2006. Huanglongbing: A destructive, newly-emerging, century-old disease of citrus. J. Plant Pathol. 88:7-37.

Brennan, E. B., Weinbaum, S. A., and Pinney, K. 2001. A new technique for studying the stylet tracks of homopteran insects in hand-sectioned plant tissue using light or epifluorescence microscopy. Biotech. Histochem. 76:59-66.

Coletta-Filho, H. D., Targon, M. L. P. N., Takita, M. A., De Negri, J. D., Pompeu, J., Jr., Machado, M. A., do Amaral, A. M., Muller, G. W. 2004. First report of the causal agent of Huanglongbing ('Candidatus Liberibacter asiaticus') in Brazil. Plant Dis. 88:1382. 
Gottwald, T. R. 2010. Current epidemiological understanding of citrus Huanglongbing. Annu. Rev. Phytopathol. 48:119-139.

Gottwald, T. R., da Graça, J. V., and Bassanezi, R. B. 2007. Citrus Huanglongbing: The pathogen and its impact. Plant Health Prog. 8:31.

Grafton-Cardwell, E. E., Stelinski, L. L., and Stansly, P. A. 2013. Biology and management of Asian citrus psyllid, vector of the Huanglongbing pathogens. Annu. Rev. Entomol. 58:413-432.

Halbert, S. E. 2005. The discovery of Huanglongbing in Florida. Second International Citrus Canker and Huanglongbing Conference, Orlando, FL.

Hung, T.-H., Hung, S.-C., Chen, C.-N., Hsu, M.-H., and Su, H.-J. 2004. Detection by PCR of 'Candidatus Liberibacter asiaticus', the bacterium causing citrus huanglongbing in vector psyllids: Application to the study of vector-pathogen relationships. Plant Pathol. 53:96-102.

Inoue, H., Ohnishi, J., Ito, T., Tomimura, K., Miyata, S., Iwanami, T., and Ashihara, W. 2009. Enhanced proliferation and efficient transmission of 'Candidatus Liberibacter asiaticus' by adult Diaphorina citri after acquisition feeding in the nymphal stage. Ann. Appl. Biol. 155:29-36.

Lee, H. A. 1921. The relation of stocks to mottled leaf of citrus leaves. Philipp. J. Sci. 18:85-95.

Lee, J. A., Halbert, S. E., Dawson, W. O., Robertson, C. J., Keesling, J. E., and Singer, B. H. 2015. Asymptomatic spread of huanglongbing and implications for disease control. Proc. Natl. Acad. Sci. 112:7605-7610.

Li, W., Hartung, J. S., and Levy, L. 2006. Quantitative real-time PCR for detection and identification of Candidatus Liberibacter species associated with citrus huanglongbing. J. Microbiol. Methods 66:104-115.

Miles, P. W. 1972. The saliva of Hemiptera. Adv. Insect Phys. 9:183-255.

Milne, A. E., Teiken, C., Deledalle, F., van den Bosch, F., Gottwald, T., and McRoberts, N. 2018. Growers' risk perception and trust in control options for huanglongbing citrus-disease in Florida and California. Crop Prot. 114:177-186.

Miranda, M. P., Fereres, A., Appezzato-Da-Gloria, B., and Lopes, J. R. S. 2009. Characterization of electrical penetration graphs of Bucephalogonia xanthophis, a vector of Xylella fastidiosa in citrus. Entomol. Exp. Appl. 130:35-46.

Morgan, J. K., Luzio, G. A., Ammar, E. D., Hunter, W. B., Hall, D. G., and Shatters, R. G. 2013. Formation of Stylet sheaths in āere (in air) from eight species of phytophagous hemipterans from six families (suborders: Auchenorrhyncha and Sternorrhyncha). PLoS One 8:e62444.

Oberholzer, P., Von Standen, D., and Basson, W. 1965. Greening disease of sweet orange in South Africa. Pages 213-219 in: Proceedings of the Third Conference of the International Organization of Citrus Virologists.

Pelz-Stelinski, K. S., Brlansky, R. H., Ebert, T. A., and Rogers, M. E. 2010. Transmission parameters for 'Candidatus Liberibacter asiaticus' by Asian citrus psyllid (hemiptera: psyllidae). J. Econ. Entomol. 103:1531-1541.

Raychaudhuri, S. P., Nariani, T. K., and Lele, V. C. 1969. Citrus die-back problem in India. Pages 1433-1437 in: Proceedings of the First International Citrus Symposium. H. D. Chapman, ed. University of California, Riverside, CA.
Reinking, O. A. 1919. Diseases of economic plants in southern China. Philipp. Agric. 8:109-134.

Sambrook, J., Fritsch, E. F., and Maniatis, T. A. 1989. Molecular Cloning: A Laboratory Manual, 2nd Ed. Cold Spring Harbor Laboratory Press, Cold Spring Harbor, NY.

Tatineni, S., Sagaram, U. S., Gowda, S., Robertson, C. J., Dawson, W. O., Iwanami, T., and Wang, N. 2008. In planta distribution of 'Candidatus Liberibacter asiaticus' as revealed by polymerase chain reaction (PCR) and real-time PCR. Phytopathology 98:592-599.

Texeira, D. C., Ayres, J., Kitajima, E. W., Danet, L., Jagoueix-Eveillard, S., Saillard, C., and Bové, J. M. 2005. First report of a Huanglongbing-like disease of citrus in Sao Paulo State, Brazil and association of a new Liberibacter species, 'Candidatus Liberibacter americanus', with the disease. Plant Dis. 89:107.

Trivedi, P., Sagaram, U. S., Kim, J.-S., Brlansky, R. H., Rogers, M. E., Stelinski, L. L., Oswalt, C., and Wang, N. 2009. Quantification of viable 'Candidatus Liberibacter asiaticus' in hosts using quantitative PCR with the aid of ethidium monoazide (EMA). Eur. J. Plant Pathol. 124: 553-563.

van der Westhuizen, A. J., Qian, X. M., and Botha, A. M. 1998. Differential induction of apoplastic peroxidase and chitinase activities in susceptible and resistant wheat cultivars by russian wheat aphid infestation. Plant Cell Rep. 18:132-137.

Wang, N., Pierson, E. A., Setubal, J. C., Xu, J., Levy, J. G., Zhang, Y., Li, J., Rangel, L. T., and Martins, J. 2017. The Candidatus Liberibacter-host interface: Insights into pathogenesis mechanisms and disease control. Annu. Rev. Phytopathol. 55:451-482.

Wang, N., and Trivedi, P. 2013. Citrus Huanglongbing: A newly relevant disease presents unprecedented challenges. Phytopathology 103:652-665.

Wang, Y., Tang, M., Hao, P., Yang, Z., Zhu, L., and He, G. 2008. Penetration into rice tissues by brown planthopper and fine structure of the salivary sheaths. Entomol. Exp. Appl. 129:295-307.

Wang, Z., Yin, Y., Hu, H., Yuan, Q., Peng, G., and Xia, Y. 2006. Development and application of molecular-based diagnosis for 'Candidatus Liberibacter asiaticus', the causal pathogen of citrus huanglongbing. Plant Pathol. 55: 630-638.

Will, T., Steckbauer, K., Hardt, M., and Van Bel, A. J. E. 2012. Aphid gel saliva: Sheath structure, protein composition and secretory dependence on stylet-tip milieu. PLoS One 7:e46903.

Xu, C. F., Xia, Y. H., Li, K. B., and Ke, C. 1988. Further study of the transmission of citrus huanglongbing by a psyllid, Diaphorina citri Kuwayama. Pages 243-248 in: Proceedings of the 10th Conference of the International Organization of Citrus Virologists. University of California, Riverside, CA.

Yu, X., and Killiny, N. 2018. The secreted salivary proteome of Asian citrus psyllid Diaphorina citri. Physiol. Entomol. 43:324-333. 